\title{
A study of the Role of 25 Hydroxy-Cholecalciferol Level on Non Alcoholic Fatty Liver Disease (NAFLD) in a Cohort of Egyptian Patients
}

\author{
Elsayed Saad Abd elbaser, MD \\ Tropical Medicine Department, Faculty of Medicine, Zagazig University, Zagazig, Egypt.
}

Corresponding Author Elsayed Saad Abd elbaser

Mobile: 01094986320

Email:
dr.sayedsaad79@
gmail.com

Key words: NAFLD, vitamin D supplementation, fatty liver
Background and study aim: Epidemiological and experimental data correlated hypovitaminosis $\mathrm{D}$ to the pathogenesis of NAFLD. So, the aim of this study was to evaluate the role of vitamin $D$ in NAFLD patients with hypovitaminosis D.

Patients and Methods: We studied 78 consecutive patients with biopsy-proven NAFLD. Patients were divided into 2 groups according to serum level of 25 $(\mathrm{OH}) \mathrm{D}$; group I; have deficient $25(\mathrm{OH})$ vitamin $\mathrm{D}(<50 \mathrm{nmo} / \mathrm{L})$ and group II; have sufficient $25(\mathrm{OH})$ vitamin D (50-70 $\mathrm{nmol} / \mathrm{L})$. Liver injury profile (ALT, AST), lipid profile (LDL, HDL and triglycerides), inflammatory marker (CRP) as well as histopathological assessment according to NAS scoring were evaluated at baseline. Vitamin D supplementation for 24 weeks

\section{INTRODUCTION}

Non-alcoholic fatty liver disease (NAFLD) has become the most common chronic liver disease worldwide [1], with an estimated prevalence of 20$30 \%$ in general population and $75 \%$ in patients with type $2 \mathrm{DM}$, obesity and metabolic syndrome [2,3]. NAFLD is a pathological condition characterized by aberrant triglycerides accumulating in the hepatocytes, in some cases accompanied by necro-inflammatory activity and fibrosis (steatohepatitis) and potentially evolving into liver cirrhosis [4]. However, beside lifestyle intervention, no established therapy of NAFLD has been identified yet [5]. Non-alcoholic fatty liver disease is the hepatic component of metabolic syndrome where the insulin resistance increases non esterified fatty acids was given for both populations with follow up evaluation of laboratory parameters at the end of the study.

Results: Patients with deficient $25(\mathrm{OH})$ vitamin D levels had significantly more severe NAFLD than those with sufficient $25(\mathrm{OH})$ vitamin $\mathrm{D}$ levels at baseline. After 24 weeks of high dose vitamin D supplementation there was significant improvement in lipid profile (LDL, HDL, and triglycerides), hepatic transaminases (ALT, AST) and CRP in NAFLD patients with hypovitaminosis $\mathrm{D}$, but no significant changes in NAFLD patients with sufficient vitamin $\mathrm{D}$.

Conclusion: Correction of hypovitaminosis D may have beneficial effects on NAFLD in patients with moderate to severe activity but no effects in case of sufficient vitamin D.

release from adipose tissue and favor their deposition into hepatocytes [6].

Low vitamin D levels have been associated with the histological severity of NAFLD/NASH [7]. Overall, a $26 \%$ additional risk for vitamin $\mathrm{D}$ deficiency has been reported in NAFLD subjects [8]. A strong epidemiological overlap also exists between NAFLD and hypovitaminosis D prevalence, as both conditions are widely spread among obese dysmetabolic individuals [9]. It has been recently recognized that vitamin $\mathrm{D}$ has other functions in addition to its role in bone metabolism [10]. It has an emerging role in regulating inflammation and immunomodulation $[\mathbf{1 1 , 1 2 ]}$. Also, it is known to suppress pro-inflammatory cytokines and increases IL-10 level [13]. 
Furthermore, data from meta-analyses point towards the existence of an association between low circulating vitamin D levels and NAFLD [8]. However, Sharifi et al. [14] and Barchetta et al. [15] reported no beneficial effect of vitamin D supplementation in NAFLD patients.

So, the aim of the present study was to evaluate the effect of vitamin D supplementation on specific sub-populations of patients with fatty liver not studied in the previous trials, namely NAFLD patients with moderate to severe liver disease.

\section{PATIENTS AND METHODS}

Study population was recruited among patients referred to hepatology clinic of Zagazig university hospitals, Egypt. Between December 2016 and June 2017, 78 patients proved to have NAFLD were divided according to $25(\mathrm{OH})$ cholecalciferol serum level into 2 groups: Group I: patients have deficient $25(\mathrm{OH})$ cholecalciferol level $(<50 \mathrm{nmol} / \mathrm{L})$. Group II: patients have sufficient but sub-optimal $25(\mathrm{OH})$ cholecalciferol level (50-75 nmol/L).

To be eligible for the study, patients had to satisfy the following criteria: fatty liver detected by abdominal ultrasonography (US) and confirmed by histopathology, ALT is more than AST, negative tests for HBsAg and HCV Abs.

\section{Exclusion criteria include :}

History of alcohol abuse (as defined by an average daily consumption of alcohol $>30 \mathrm{~g} /$ day in men and $>20 \mathrm{~g} /$ day in women), cirrhosis, autoimmune hepatitis and other causes of liver disease (hemochromatosis, Wilson's disease), hyper/ hypoparathyroidism, known hypersensitivity to cholecalciferol, hypercalcemia, hypercalciuria, nephrolithiasis, nephrocalcinosis.

All patients were subjected to:

1- Thorough history taking with full clinical examination and all medications were carefully recorded at baseline visits and drug alterations regarding anti-diabetic agents, anti-hypertensive treatments. Statins were not allowed throughout the study.

2- The body mass index (BMI) was calculated as weight in kilograms divided by the square of the height in meters.

3- Serum $25(\mathrm{OH})$-cholecalciferol was measured as an indicator of vitamin D status [16].
4- Liver ultrasound scanning was performed to assess the presence of hepatic steatosis.

5- Evaluation of lipid profile (LDL, HDL, triglycerides), glycemic control (HbA1c \%) and liver enzymes (ALT, AST) before and after vitamin D supplementation.

6- Liver biopsy for all patients at base line, to confirm the diagnosis and for histological grading of NAFLD, using Kleiner NAFLD activity score (NAS). This score is the sum of three histological components; steatosis (0-3), lobular inflammation (0-3) and ballooning degeneration (0-2). It ranges from 0 to 8 [17].

7- Vitamin D supplementation in the form of oral solution of cholecalciferol $\quad(50,000$ IU/week) for 24 weeks for both groups.

\section{Statistical Analysis}

Data were analyzed with SPSS version 16 for data processing and statistics. Quantitative data were expressed as mean \pm standard deviation (SD) and were analyzed by independent $t$ test for unpaired data. Paired quantitative data were analyzed by paired t test. While Wilcoxon test has been used to analyze qualitative paired data and Man-Whitney test has been used for qualitative unpaired data. P-value was considered significant if $<0.05$ and highly significant if $<0.001$.

\section{Ethical Considerations}

Since the patients have elevated liver enzymes with no obvious cause, some patients had family history of liver diseases and liver malignancy and imaging evident of focal fat and focal sparing, liver biopsies were done to detect the underlying cause and written consent was obtained from all patients before the study.

The study protocol was reviewed and approved by the Institutional Review Board of the faculty of Medicine, Zagazig University, Egypt.

\section{RESULTS}

Out of 78 patients who met the inclusion criteria of the study, 40 patients had deficient $25(\mathrm{OH})$ cholecalciferol $(<50 \mathrm{nmol} / \mathrm{L})$ and allocated to group I, while 38 patients had sufficient but suboptimal $25(\mathrm{OH})$ cholecalciferol $(50-75 \mathrm{nmol} / \mathrm{L})$ and allocated to group II (mean for group I; $21.41 \pm 12.3$ vs. group II; $61.97 \pm 6.84$, while the 
mean for healthy subjects was $73 \pm 7.53$ ) (Figure 1). No major adverse events occurred during the study, highlighting safety of the dosing and no change in the ongoing therapies throughout the study. Regarding the cause of NAFLD, there was no statistically significant difference between both populations (data were not shown).

The mean age of all patients was $41.14 \pm 9.88$ years with males represented $65 \%$. Both groups were age and sex matched. After oral cholecalciferol supplementation, serum $25(\mathrm{OH})$ D levels significantly increased in both groups (mean for group I; $21.41 \pm 12.3$ to $45.2 \pm 12.5$ vs. mean for group II; $61.97 \pm 6.84$ to $77.42 \pm 20.1$ ).

As regard baseline biochemical parameters, there were statistically significant increases in LDL; $(133.2 \pm 43.69$ vs. $101.61 \pm 22.18$, p value $<0.001)$, triglycerides; $(185.8 \pm 73.6$ vs. $124.1 \pm 34.1$, $\mathrm{p}$ value $<0.001$ ), transaminases (ALT; $65.26 \pm 38.88$ vs. 49.66 \pm 26.10 , $\mathrm{P}$ value; 0.042 , AST; $55.13 \pm 22.08$ vs. $40.71 \pm 25.26$, $P$ value; $<0.001)$, and histological grading in group I when compared to group II, while HDL showed statistically significant decrease (38.88 \pm 9.98 vs. $44.32 \pm 7.62$, p value 0.008 ).
After 24 weeks of vitamin D supplementation, there was statistically significant improvement in LDL, HDL, triglycerides, ALT and AST in group I (Table 2), while there was non-significant change in group II (Table 2).

Finally, it was noted that at baseline there was non-significant difference between both groups regarding the anti-inflammatory marker (CRP); $3.4 \pm 1.3$ vs. $3.4 \pm 1.3$, p value 0.213 . After vitamin D supplementation there was statistically significant improvement of CRP in both populations.

When comparing both groups after vitamin D supplementation, there were non-significant differences regarding hepatic indicators, lipid profile and $\mathrm{HbA} 1 \mathrm{c} \%$, but there were significant differences in CRP (Table 3).

Moreover, we performed a correlation analysis that showed a significant association between NAFLD scores, serum 25(OH)-cholecalciferol levels, lipid profile and histological grading (Table 4).

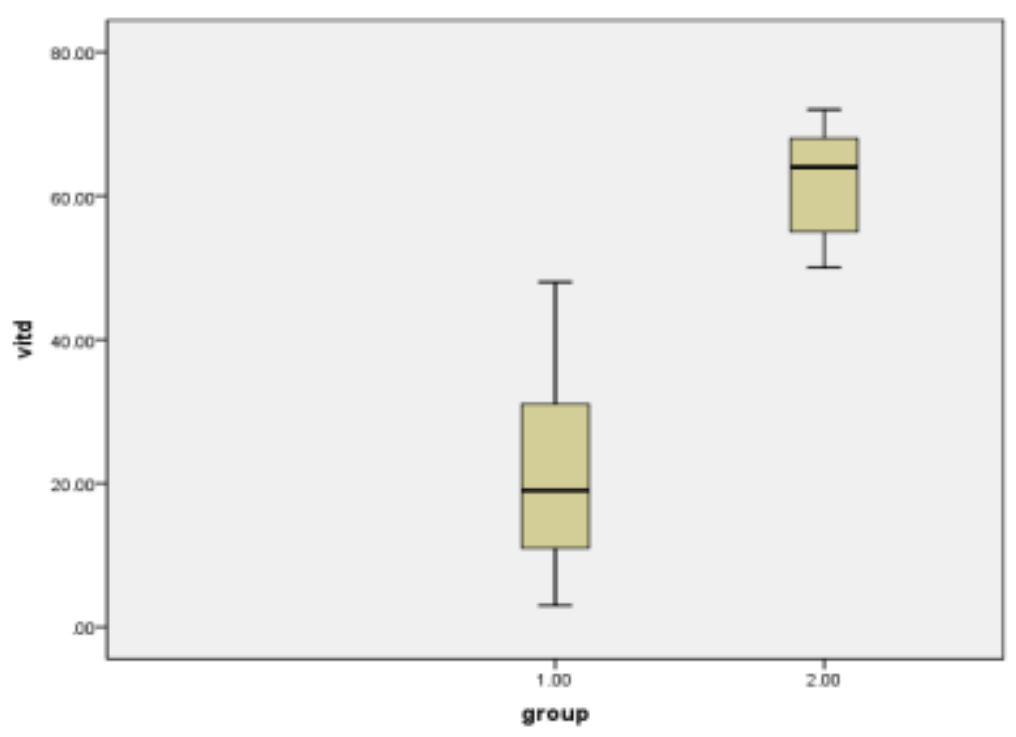

Figure 1: vitamin D levels among both populations 
Table (1); Baseline clinical and biochemical characteristics of both groups:

\begin{tabular}{|l|l|l|l|}
\hline & \multicolumn{1}{|c|}{$\begin{array}{c}\text { Group I } \\
\mathbf{N O = 4 0 )} \\
\mathbf{X} \pm \text { SD }\end{array}$} & \multicolumn{1}{|c|}{$\begin{array}{c}\text { Group II } \\
(\mathbf{N O = 3 8}) \\
\mathbf{X} \pm \text { SD }\end{array}$} & \multicolumn{1}{|c|}{ P value } \\
\hline Age & $41.70 \pm 9.66$ & $40.58 \pm 10.10$ & 0.619 \\
\hline Gender & $\begin{array}{l}\text { Male: } 28 \\
\text { Female: } 12\end{array}$ & $\begin{array}{l}\text { Male:23 } \\
\text { Female }: 15\end{array}$ & 0.477 \\
\hline BMI & $29.190 \pm 2.337$ & $28.979 \pm 3.143$ & 0.739 \\
\hline 25 (OH) D (nmol/L) & $21.41 \pm 12.30$ & $61.97 \pm 6.84$ & $<0.001$ \\
\hline LDL $(\mathrm{mg} / \mathrm{dl})$ & $133.2 \pm 43.69$ & $101.61 \pm 22.18$ & $<0.001$ \\
\hline HDL $(\mathrm{mg} / \mathrm{dl})$ & $38.88 \pm 9.98$ & $44.32 \pm 7.62$ & 0.008 \\
\hline Triglycerides $(\mathrm{mg} / \mathrm{dl})$ & $185.8 \pm 73.6$ & $124.1 \pm 34.1$ & $<0.001$ \\
\hline HbA1c $(\% / m m o l / m o l)$ & $8.17 \pm 1.67$ & $7.31 \pm 2.27$ & 0.062 \\
\hline AST $(\mathrm{IU} / \mathrm{l})$ & $55.13 \pm 22.08$ & $40.71 \pm 25.26$ & 0.009 \\
\hline ALT $(\mathrm{IU} / \mathrm{l})$ & $65.26 \pm 38.88$ & $49.66 \pm 26.10$ & 0.042 \\
\hline CRP $(\mathrm{mg} / \mathrm{dl})$ & $3.4 \pm 1.3$ & $3 \pm 1.5$ & 0.213 \\
\hline NAS & $5 \pm 2.05$ & $3 \pm 2$ & $<0.001$ \\
\hline
\end{tabular}

Table 2: Comparison of characteristics before and after study treatment in both groups

\begin{tabular}{|c|c|c|c|c|c|c|}
\hline & \multicolumn{2}{|c|}{$\begin{array}{l}\text { Group I } \\
(\text { No=40) }\end{array}$} & \multirow{2}{*}{$\mathbf{P}$} & \multicolumn{2}{|c|}{$\begin{array}{c}\begin{array}{c}\text { Group II } \\
(\mathrm{No}=38)\end{array} \\
\end{array}$} & \multirow{2}{*}{$\mathbf{P}$} \\
\hline & $\begin{array}{c}\text { Baseline } \\
\mathrm{X} \pm \text { SD }\end{array}$ & $\begin{array}{c}24 \text { weeks } \\
\text { X } \pm \text { SD }\end{array}$ & & $\begin{array}{c}\text { Baseline } \\
\mathrm{X} \pm \text { SD }\end{array}$ & $\begin{array}{c}24 \text { weeks } \\
\text { X } \pm \text { SD }\end{array}$ & \\
\hline Vitamin D(nmol/L) & $21.41 \pm 12.30$ & $45.20 \pm 12.46$ & $<.001$ & $61.97 \pm 6.84$ & $81.5 \pm 9.27$ & $<.001$ \\
\hline$\overline{\text { ALT (IU/I) }}$ & $65.26 \pm 38.88$ & $50.05 \pm 28.04$ & $\begin{array}{c}.001 \\
\end{array}$ & $49.66 \pm 26.10$ & $48.34 \pm 22.45$ & 0.699 \\
\hline$\overline{\text { AST (IU/I) }}$ & $55.13 \pm 22.08$ & $35.42 \pm 19.32$ & $\begin{array}{c}.001 \\
\end{array}$ & $40.71 \pm 25.26$ & $40.68 \pm 23.52$ & .914 \\
\hline LDL (mg/dl) & $133.20 \pm 43.6$ & $115.96 \pm 35.24$ & $<.001$ & $97.79 \pm 16.22$ & $98.05 \pm 16.07$ & 0.826 \\
\hline HDL (mg/dl) & $38.88 \pm 9.98$ & $41.91 \pm 7.66$ & $<.003$ & $44.76 \pm 7.02$ & $45.08 \pm 6.71$ & 0.275 \\
\hline Triglycerides (mg/dl) & $185.8 \pm 73.6$ & $139.3 \pm 68$ & $<.001$ & $124.13 \pm 34.13$ & $122.61 \pm 31.1$ & 0.250 \\
\hline HbA1c\% (\%/mmol/mol) & $8.17 \pm 1.67$ & $6.70 \pm 1.52$ & $<0.046$ & $7.31 \pm 2.27$ & $6.69 \pm 1.52$ & 0.157 \\
\hline CRP (mg/dl) & $3.4 \pm 1.3$ & $1 \pm 0.6$ & $<0.001$ & $3 \pm 1.5$ & $1.5 \pm 0.8$ & $\overline{<0.001}$ \\
\hline
\end{tabular}



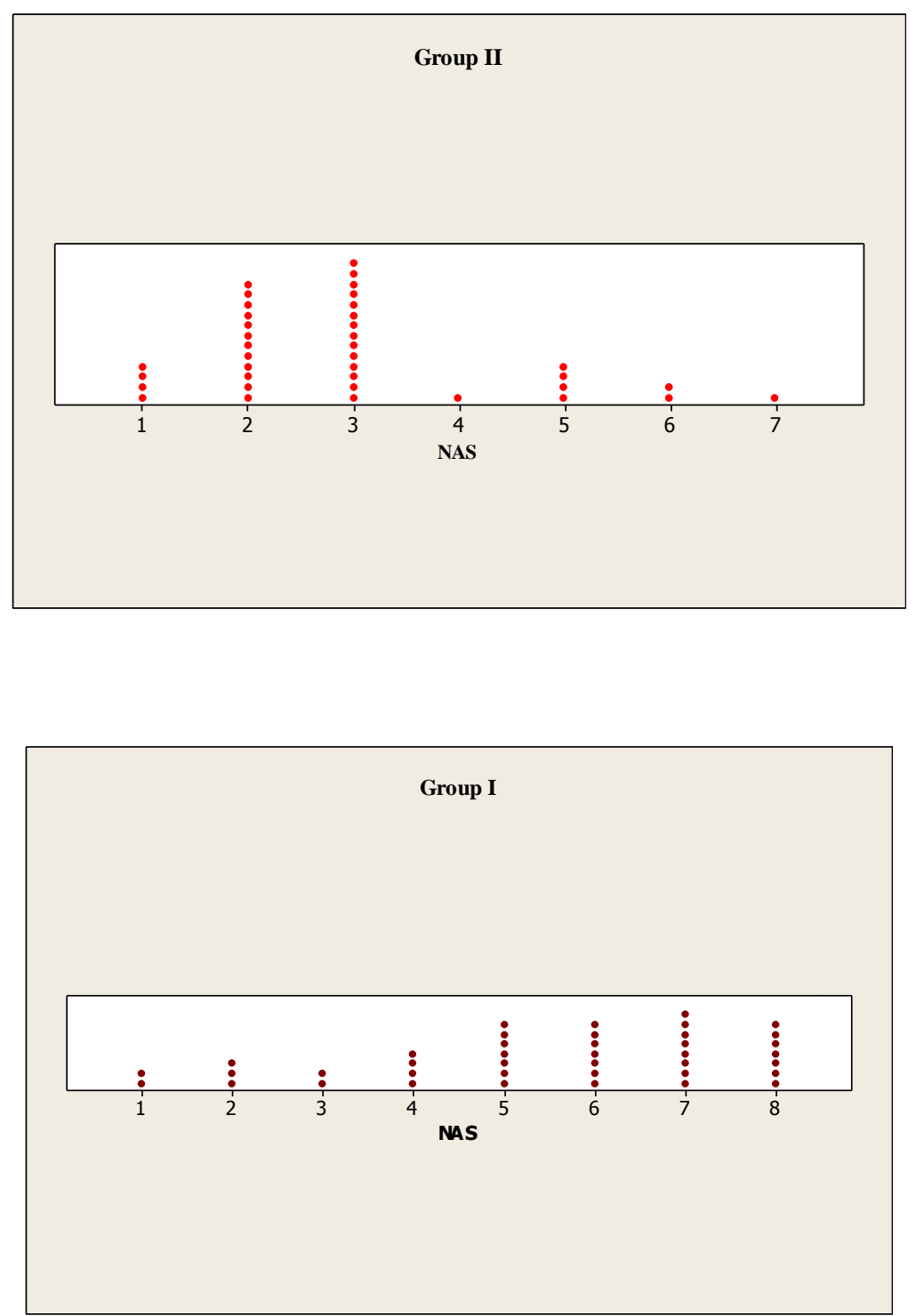

Figure 2: Distribution of NASH according to activity grade.

Table 3 : Biochemical characteristics after vitamin D supplementation in both groups

\begin{tabular}{|c|c|c|c|c|}
\hline & $\begin{array}{c}\text { Group I } \\
\text { NO=40 } \\
\mathrm{X} \pm \text { SD }\end{array}$ & $\begin{array}{c}\text { Group II } \\
\text { NO=38 } \\
\mathrm{X} \pm \mathrm{SD}\end{array}$ & T test & $P$ value \\
\hline Vitamin D (nmol/L) & $45.20 \pm 12.5$ & $77.42 \pm 20.1$ & -8.61 & $<0.01$ \\
\hline ALT (IU/l) & $50.05 \pm 28.04$ & $48.34 \pm 22.5$ & 0.30 & 0.768 \\
\hline AST (IU/l) & $35.42 \pm 19.32$ & $40.68 \pm 9.67$ & -1.51 & 0.136 \\
\hline $\mathrm{LDL}(\mathrm{mg} / \mathrm{dl})$ & $106.1 \pm 24.4$ & $98.1 \pm 16.1$ & 1.73 & 0.088 \\
\hline $\mathrm{HDL}(\mathrm{mg} / \mathrm{dl})$ & $41.91 \pm 7.66$ & $45.08 \pm 6.71$ & -1.95 & 0.055 \\
\hline Triglycerides $(\mathrm{mg} / \mathrm{dl})$ & $139.1 \pm 55$ & $122.6 \pm 31.1$ & 1.64 & 0.106 \\
\hline $\mathrm{HbA} 1 \mathrm{c} \%(\% / \mathrm{mmol} / \mathrm{mol})$ & $6.70 \pm 1.51$ & $6.69 \pm 1.52$ & 0.03 & 0.977 \\
\hline $\mathrm{CRP}(\mathrm{mg} / \mathrm{dl})$ & $1 \pm 0.6$ & $1.5 \pm 0.8$ & 22.36 & $<0.001$ \\
\hline
\end{tabular}


Table 4: Correlation between vitamin D and different parameters before vitamin D supplementation

\begin{tabular}{|l|c|c|}
\hline \multicolumn{1}{|c|}{ Term } & Coefficient & P value \\
\hline BMI & -0.069 & .548 \\
\hline LDL & -0.530 & $<0.001$ \\
\hline HDL & 0.402 & $<0.001$ \\
\hline Triglycerides & -0.545 & $<0.001$ \\
\hline NAS & -0.928 & $<0.001$ \\
\hline
\end{tabular}

\section{DISCUSSION}

Vitamin D has been proposed as a potential therapeutic option for liver damage in NAFLD and non-alcoholic steatohepatitis (NASH) [18]. However, most studies aiming to test the efficacy of high dose vitamin $\mathrm{D}$ supplementation on NAFLD did not obtain any improvement in either fatty liver content, histological parameters related to NASH, or transaminases [19]. The present study was designed to investigate the role of 24-week oral vitamin D on specific group of NAFLD patients.

In this study, all subjects affected by NAFLD have sub-optimal serum $25(\mathrm{OH})$-cholecalciferol levels compared to age and sex matched subjects (data not shown); however, subjects with deficient levels display a significantly more severe liver disease than those with sufficient levels. Previously, an association between low $25(\mathrm{OH})$-cholecalciferol levels and the histological severity of NASH was suggested by Targher et al. [7].

In this study, participants were recruited among patients referred to hepatology clinic. This allowed selection of patients with more severe liver disease as compared to those studied in previous trials $[\mathbf{1 4 , 1 5 ]}$. The baseline biochemical tests as well as the histological activities were significantly different among study populations.

While vitamin D supplementation in the form of oral cholecalciferol (50,000 IU/week) for 24 weeks had beneficial effects on hepatic injury indicators, metabolic profile and CRP among patients with hypovitaminosis $\mathrm{D}$, it could not restore the advanced liver injury among control patients with sufficient vitamin D.

In another study, similar response in patients with normal or reduced $25(\mathrm{OH})$-cholecalciferol levels at the baseline was observed after vitamin D supplementation [15]. The reasons for this discrepancy between the results may be due to the differences in the disease activity, duration of the disease, doses of vitamin D supplementation and other possible cellular mechanisms between vitamin D and inflammatory cytokines not fully understood.

Also, Sharifi et al. [14] had reported that, twice a month 16-weeks cholecalciferol supplementation had no effects compared to placebo on aminotransferases, and insulin resistance in nondiabetic subjects selected on the basis of USdetected fatty liver and upper normal ALT levels. In this study, the intervention was limited to 4 months and the dose of cholecalciferol was $50.000 \mathrm{IU} / 2$ weeks. Moreover the disease activity was mild. These differences may explain the discrepancy with the recent study.

On the other hand, although there was no statistically significant difference at baseline regarding CRP, there was significant improvement in CRP among all patients, high lightening the anti-inflammatory effect of vitamin D [21]. In agreement with this result, significant improvement of the inflammatory marker (hs.CRP) has been reported after vitamin $\mathrm{D}$ supplementation in NAFLD patients [14].

Serum vitamin D is inversely correlated to lipid profile and histological grading (table 4) in our study as well as other published reports [7].

\section{CONCLUSION}

Correction of hypovitaminosis D may has beneficial effects in NAFLD patients with moderate to severe activity, while vitamin D supplementation has no effect on NAFLD patients with sufficient vitamin D level. Larger, randomized, placebocontrolled trials are required to better evaluate the efficacy of vitamin D supplementation on NAFLD. 


\section{REFERENCES}

1. Clark JM, Brancati FL, Diehl AME. Nonalcoholic fatty liver disease: the most common cause of abnormal liver enzymes in the US population. Gastroenterology. 2011; 120(5 Suppl 1):A65.

2. Bedogni G, Miglioli L, Masutti F, Castiglione A, Crocè LS, Tiribelli $\mathrm{C}$, et al. Incidence and natural course of fatty liver in the general population: the Dionysos study. Hepatology 2007, 46:1387-1391. 11.

3. Gupte P, Amarapurkar D, Agal S, Baijal R, Kulshrestha P, Pramanik S, et al. Non-alcoholic steatohepatitis in type 2 diabetes mellitus. Journal of Gastroenterology and Hepatology 2004, 19:854-858.

4. Bugianesi E, Leone N, Vanni E, Marchesini G, Brunello F, Carucci P, Musso A et al. Expanding the natural history of Non Alcoholic Steatohepatitis: from cryptogenic cirrhosis to hepatocellular carcinoma. Gastroenterology, 2002; 123(1):13440

5. Liyanagedera, S; Williams, RP; Veraldi, S; Nobili, V; Mann, JP. The Pharmacological Management of NAFLD in Children and Adolescents. Expert Rev. Clin. Pharmacol. 2017, 21, 1-13.

6. Fujita K, Nozaki Y, Wada K, Yoneda M, Fujimoto Y, Fujitake M, et al. Dysfunctional very-lowdensity lipoprotein synthesis and release is a key factor in nonalcoholic steatohepatitis pathogenesis. Hepatology 2009, 50:772-780.

7. Targher, G; Bertolini, L; Scala, L; Cigolini, M; Zenari, L; Falezza, G; Arcaro, G. Associations between serum 25-hydroxyvitamin D3 concentrations and liver histology in patients with non-alcoholic fatty liver disease. Nutr. Metab. Cardiovasc. Dis. 2007, 17, 517-524.

8. Eliades, M; Spyrou, E; Agrawal, N; Lazo, M; Brancati, FL; Potter, JJ; Koteish, AA; Clark, JM; Guallar, E; Hernaez, R. Meta-analysis: Vitamin D and non-alcoholic fatty liver disease. Aliment. Pharmacol. Ther. 2013, 38, 246-254.

9. Barchetta, I; De Bernardinis, M; Capoccia, D; Baroni, MG; Fontana, M; Fraioli, A; Morini, S; Leonetti, F; Cavallo, MG. Hypovitaminosis D is independently associated with metabolic syndrome in obese patients. PLOS ONE 2013, 8, e68689.

10. DeLuca HF: Overview of general physiologic features and functions of vitamin D. Am J Clin Nutr 2004, 80:1689S-1696S.

11. George PS, Pearson ER, Witham MD. Effect of vitamin D supplementation on glycaemic control and insulin resistance: a systematic review and meta-analysis. Diabet Med 2012; 29: e142-e150 [PMID: 22486204 DOI: 10.1111/j.1464-5491. 2012.03672 .
12. Roth CL, Elfers CT, Figlewicz DP, Melhorn SJ, Morton GJ, Hoofnagle A, Yeh MM, Nelson JE, Kowdley KV. Vitamin D deficiency in obese rats exacerbates nonalcoholic fatty liver disease and increases hepatic resistin and Toll-like receptor activation. Hepatology 2012; 55: 1103-1111

13. Cardus A, Parisi E, Gallego C, Aldea M, Fernandez E, Valdivielso JM. 1, 25-Dihydroxyvitamin D3 stimulates vascular smooth muscle cell proliferation through a VEGF-mediated pathway. Kidney Int. 2006; 69:1377-1384.

14. Sharifi N, Amani R, Hajiani E, Cheraghian B. Does vitamin $\mathrm{D}$ improve liver enzymes, oxidative stress, and inflammatory biomarkers in adults with non-alcoholic fatty liver disease? A randomized clinical trial. Endocrine. 2014; 47 (1):70-80.

15. Barchetta, I; Del Ben, M; Angelico, F; Di Martino, M; Fraioli, A; La Torre, G; Saulle, R; Perri, L; Morini, S; Tiberti, C; et al. No effects of oral vitamin D supplementation on non-alcoholic fatty liver disease in patients with type 2 diabetes: A randomized, double-blind, placebo-controlled trial. BMC Med. 2016, 14, 92.

16. Brouwer-Brolsma EM, Bischoff-Ferrari HA, Bouillon R, Feskens EJ, Gallagher CJ, Hypponen E, et al. Vitamin D: do we get enough? A discussion between vitamin $\mathrm{D}$ experts in order to make a step towards the harmonisation of dietary reference intakes for vitamin D across Europe. Osteoporos Int. 2013; 24(5):1567-77.

17. Kleiner DE, Brunt EM, Van Natta M, Behling C, Contos MJ, Cummings OW, et al. Design and validation of a histological scoring system for nonalcoholic fatty liver disease. Hepatology 2005; 41:1313-1321.

18. Nobili, V; Reif, S. Vitamin D and liver fibrosis: Let's start soon before it's too late. Gut 2015, 64, 698-699.

19. Tabrizi, R; Moosazadeh, M; Lankarani, KB; Akbari, M; Heydari, ST; Kolahdooz, F; Samimi, M; Asemi, $Z$. The effects of vitamin D supplementation on metabolic profiles and liver function in patients with non-alcoholic fatty liver disease: A systematic review and meta-analysis of randomized controlled trials. Diabetes Metab. Syndr. 2017

20. Barchetta, I; Angelico, F; Del Ben, M; Baroni, MG; Pozzilli, P; Morini, S; Cavallo, MG. Strong association between non alcoholic fatty liver disease (NAFLD) and low 25(OH) vitamin D levels in an adult population with normal serum liver enzymes. BMC Med. 2011, 9, 85

21. MT Cantorna, Y Zhu, M Froicu, A Wittke, Vitamin D status, 1, 25-dihydroxyvitamin D3, and the immune system. Am. J. Clin. Nutr. 80(6), 1717S-1720S (2004). 